\title{
Subplate cells: amplifiers of neuronal activity in the developing cerebral cortex
}

\author{
Heiko J. Luhmann*, Werner Kilb and Ileana L. Hanganu-Opatz ${ }^{\dagger}$ \\ Institute of Physiology and Pathophysiology, University Medical Center, Johannes Gutenberg University Mainz, Mainz, Germany
}

\section{Edited by:}

Kathleen S. Rockland, RIKEN Brain

Science Institute, Japan

Reviewed by:

Patrick Kanold,

University of Maryland, USA

Ivica Kostovic,

University of Zagreb, Croatia

*Correspondence:

Heiko J. Luhmann, Institute of Physiology and Pathophysiology,

University of Mainz, Duesbergweg 6,

D-55128 Mainz, Germany.

e-mail:luhmann@uni-mainz.de

${ }^{\dagger}$ Present address:

Ileana L. Hanganu-Opatz, Center for Molecular Neurobiology, University Medical Center Hamburg-Eppendorf, Martinistr. 85, 20251 Hamburg, Germany
Due to their unique structural and functional properties, subplate cells are ideally suited to function as important amplifying units within the developing neocortical circuit. Subplate neurons have extensive dendritic and axonal ramifications and relatively mature functional properties, i.e. their action potential firing can exceed frequencies of $40 \mathrm{~Hz}$. At earliest stages of corticogenesis subplate cells receive functional synaptic inputs from the thalamus and from other cortical and non-cortical sources. Glutamatergic and depolarizing GABAergic inputs arise from cortical neurons and neuromodulatory inputs arise from the basal forebrain and other sources. Activation of postsynaptic metabotropic receptors, i.e. muscarinic receptors, elicits in subplate neurons oscillatory burst discharges which are transmitted via electrical and chemical synapses to neighbouring subplate cells and to immature neurons in the cortical plate. The tonic non-synaptic release of GABA from GABAergic subplate cells facilitates the generation of burst discharges. These cellular bursts are amplified by prominent gap junction coupling in the subplate and cortical plate, thereby eliciting $10-20 \mathrm{~Hz}$ oscillations in a local columnar network. Thus, we propose that neuronal networks are organized at earliest stages in a gap junction coupled columnar syncytium. We postulate that the subplate does not only serve as a transient relay station for afferent inputs, but rather as an active element amplifying the afferent and intracortical activity.

\section{INTRODUCTION}

The subplate forms a transient layer in the developing cerebral cortex and consists of migratory and postmigratory neurons, dendrites, axons, growth cones, synapses and glial cells. The subplate is located between the intermediate zone and the cortical plate, which during further development differentiates into the neocortical layers II to VI (Figure 1A). Kostovic and Molliver were the first who identified the subplate as a distinct layer in the embryonic human cerebral cortex (Kostovic and Molliver, 1974). Subsequently Rakic (1977) described this layer in the monkey neocortex. A subplate can be identified in all mammals although its relative thickness, developmental profile and persistence in adulthood vary among species. Anatomical data indicate an evolutionary difference in the ontogenetic fate of the subplate. In the rat and other rodents many subplate cells survive into adulthood forming layer VIb or VII (Aboitiz and Montiel, 2007). Prominent species differences also exist in the relative thickness of the subplate, which increased during evolution. In humans the subplate develops to approximately six times the thickness of the cortical plate around 29 weeks of gestation (Mrzljak et al., 1990), whereas in rodents it remains a relatively thin layer during development (Uylings et al., 1990). The majority of the subplate cells are born early before the first cortical plate neurons (Luskin and Shatz, 1985; Valverde et al., 1989). In rodents subplate neurons may be also generated later in development (Hevner et al., 2004). A substantial proportion of subplate cells are not born in the ventricular neuroepithelium, but instead originate in the medial ganglionic eminence and follow a tangential migratory route to their positions in the developing cortex (Lavdas et al., 1999). Subplate cells represent a rather heterogeneous neuronal population according to their morphology, neurotransmitter identity and connectivity (for review Allendoerfer and Shatz, 1994).

Subplate cells play important roles in the structural and functional organization of the cerebral cortex and in early necortical plasticity. Axons arising from subplate neurons pioneer the corticofugal pathway and have been proposed to form a cellular scaffold for guiding thalamocortical axons (McConnell et al., 1989; Ghosh et al., 1990) (for review Allendoerfer and Shatz, 1994; Molnár, 1998). Subplate neurons receive a transient synaptic input from "waiting" thalamic axons (Lund and Mustari, 1977; Rakic, 1977, 1983) and early deletion of subplate neurons in kitten visual cortex prevents the segregation of thalamocortical axons within layer IV and the formation of ocular dominance columns (Ghosh and Shatz, 1992; Kanold et al., 2003). Furthermore, subplate cells regulate the maturation of GABAergic synaptic transmission and establish the balance between excitation and inhibition in the developing neocortical network (Kanold and Shatz, 2006).

\section{STRUCTURAL PROPERTIES OF SUBPLATE NEURONS}

Subplate neurons reveal a large variety of morphologies (Figure 1B) (Hanganu et al., 2002). Inverted pyramidal-like and horizontal cells as well as polymorphic neurons with different shapes and spiny or smooth dendrites have been classified as subplate neurons (Kostovic and Rakic, 1980; Wahle et al., 1987; Valverde et al., 1989; Kostovic and Rakic, 1990). Due to their earlier generation and more mature developmental stage, subplate neurons show a relatively extensive dendritic tree when compared to the more immature pyramidal 
A

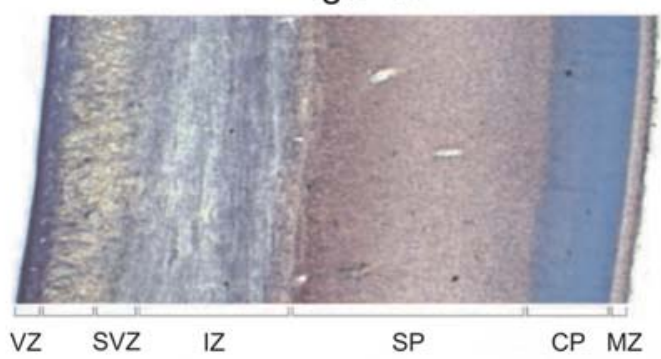

E45



$\mathrm{E} 31 / 32$

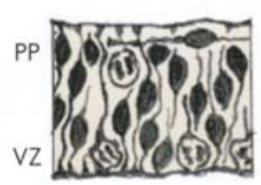

PP

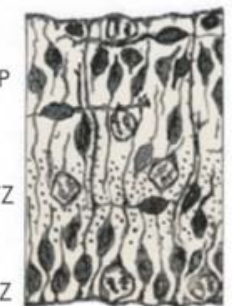

E55

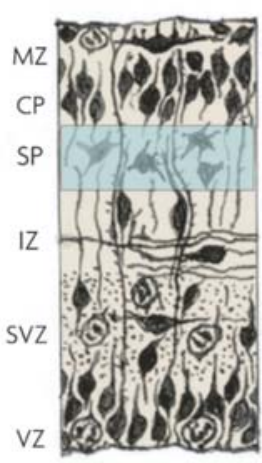

gw 14

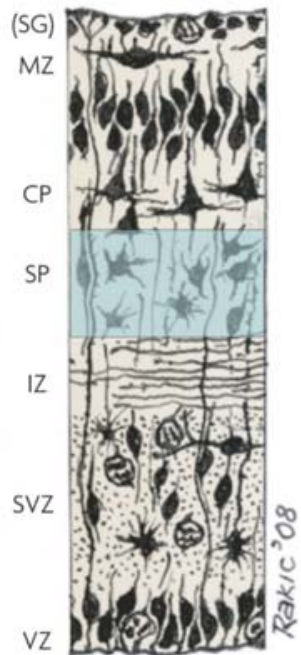

B
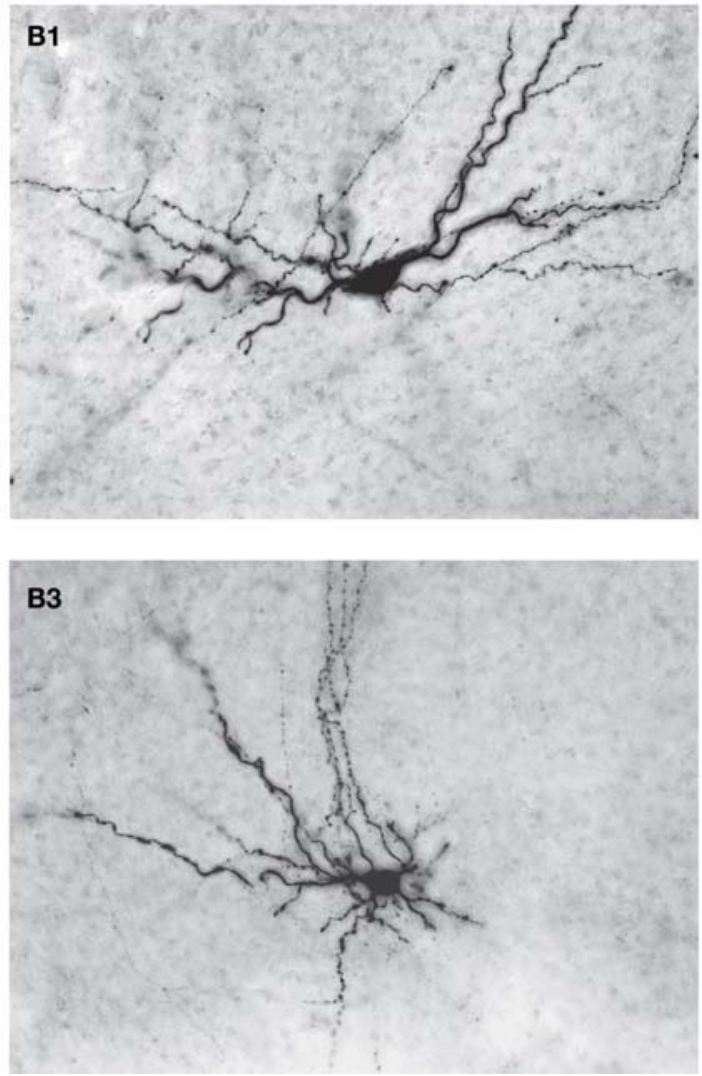

FIGURE 1 | Emergence of the subplate during neocortical development and structural diversity of subplate cells. (A) Prenatal development of the human cerebral cortex as suggested by Bystron et al. (2008). Drawing from Pasko Rakic. Photograph shows coronal brain section stained with cresyl violet of a gestational week 18 human neocortex. Note large expansion of subplate as compared to other neocortical layers. Approximate embryonic day (E) and gestational week (gw) are given for each developmental stage. CP, cortical plate; IZ, intermediate zone; $\mathrm{MZ}$, marginal zone; $\mathrm{PP}$, preplate; SP, subplate; $\mathrm{SVZ}$, subventricular zone; (SG), subpial granular layer (part of MZ); VZ, ventricular zone. (B) Morphological properties of
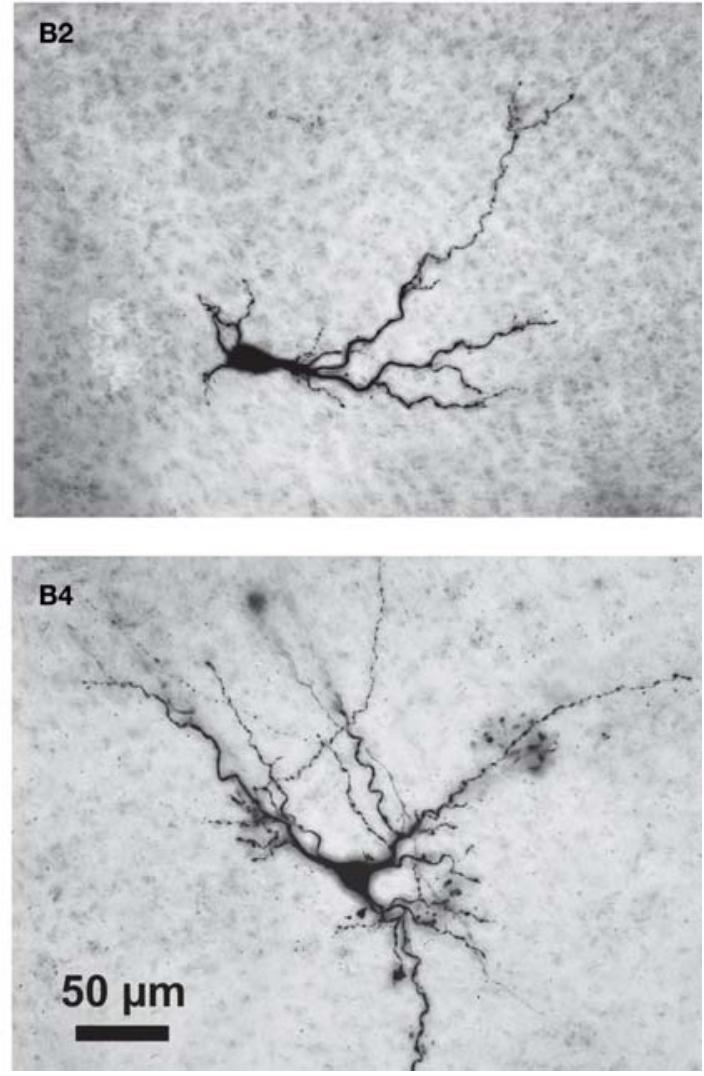

biocytin-stained subplate neurons in newborn rat cerebral cortex. (B1) Postnatal day $(P)$ three horizontal bitufted cell with large fusiform soma and primary dendrites oriented parallel to the pial surface. (B2) P2 horizontal monotufted SPn. (B3) P3 multipolar cell with extensive dendritic arborization within SP and layers VNI. (B4) P2 inverted pyramidal neuron with triangular soma and "apical" dendrite oriented towards white matter. Scale bar in (B4) corresponds to (B1-B4) and pial surface is located toward the top in all photomicrographs of (B). Reproduced and modified with permission from (Bystron et al., 2008) (A), (Kostovic et al., 2002) [photograph in (A)] and from (Hanganu et al., 2002) (B). 
neurons of the cortical plate (Mrzljak et al., 1992). Descending dendrites from subplate neurons may invade the underlying intermediate zone and ascending dendrites may extend into the cortical plate (Del Río et al., 2000). This morphological heterogeneity is accompanied by a large variation in immunoreactivity. Subplate neurons reveal markers for GABA or glutamate and may co-express various peptides (Chun et al., 1987; Finney et al., 1998). The morphological and neurochemical heterogeneity also explains, why various attempts failed to identify a specific marker for subplate neurons (Wahle et al., 1994). Recently Hoerder-Suabedissen et al. (2009) succeeded in identifying a number of novel markers for murine subplate cells, which may soon allow the definition of different subpopulations of subplate neurons.

Subplate cells participate in local and long-distance axonal connections indicating that these neurons may function as local circuit as well as projection neurons. They show a dense axonal arborization within the subplate, but also project to the marginal zone/ layer I (Clancy and Cauller, 1999) and to the cortical plate, where they form axonal collaterals within layer IV (Friauf et al., 1990). In ferrets and cats, the majority of the subplate neurons projecting into the cortical plate reside in the upper half of the subplate and provide a glutamatergic synaptic input to the developing cortical plate, including the layer IV neurons (Friauf et al., 1990; Finney et al., 1998). Long-distance axons from subplate neurons invade the thalamus during early stages of corticogenesis and form an axonal scaffold for the establishment of cortical efferent and afferent projections (McConnell et al., 1989, 1994; Kim et al., 1991; De Carlos and O'Leary, 1992). Beside these local and long-distance projections arising from glutamatergic subplate neurons, GABAergic subplate cells also project to both neighbouring and more distant neocortical regions and form a corticocortical synaptic network (Tomioka et al., 2005; Higo et al., 2007). Since GABA may act as an excitatory neurotransmitter during early cortical development (for review Ben-Ari et al., 2007), the postsynaptic action of GABAergic subplate neurons may be also depolarizing (Figure 6 in Hanganu et al., 2002).

Ultrastructural studies of subplate cells in various species have demonstrated symmetrical as well as asymmetrical synapses with relatively mature properties (Kostovic and Rakic, 1980, 1990; Chun and Shatz, 1988; Herrmann et al., 1994), indicating that subplate neurons receive GABAergic as well as glutamatergic synaptic inputs. As suggested by Kostovic and Rakic (1980), glutamatergic inputs onto subplate neurons may arise from the thalamus and other neocortical areas, whereas GABAergic synaptic inputs may originate from GABAergic interneurons in the subplate. Thalamocortical synaptic contacts with spines and shafts of subplate neuron dendrites have been demonstrated in the neonatal ferret (Herrmann et al., 1994) and a dense network of corticocortical fibers have been reported in the subplate of the embryonic mouse (Crandall and Caviness, 1984).

$N$-Methyl-D-aspartate (NMDA), $\alpha$-amino-3-hydroxy-5-methylisoxazole-4-propionic acid (AMPA) and kainate receptors and the essential subunits for their receptor function have been demonstrated in the subplate of various species, suggesting the presence of functional glutamatergic synapses in subplate neurons (Herrmann, 1996; Aoki, 1997; Catalano et al., 1997; Furuta and Martin, 1999). The expression of benzodiazepine binding sites (Schlumpf et al.,
1983), GABA receptors (Huntley et al., 1990) and GABA receptor subunits (Meinecke and Rakic, 1992) in the subplate indicate that functional GABAergic synaptic inputs should also be present in subplate neurons.

These morphological, ultrastructural and immunohistochemical data are complemented by functional studies on the properties of the subplate and single subplate cells in different mammalian species.

\section{FUNCTIONAL PROPERTIES OF SUBPLATE NEURONS}

In contrast to the heterogeneity in morphological and chemical appearance, electrophysiological recordings from single subplate neurons in rodents demonstrate rather homogeneous functional properties. Subplate neurons exhibit relatively uniform passive membrane properties. Whole-cell patch-clamp recordings from subplate cells in newborn rodent neocortical slices revealed resting membrane potentials and input resistances in the range of $-55 \mathrm{mV}$ and 1-1.2 G $\Omega$, respectively (Luhmann et al., 2000; Hanganu et al., 2001; Hirsch and Luhmann, 2008). In response to sustained depolarization by intracellular current injection, subplate neurons are capable of firing overshooting and repetitive action potentials at frequencies exceeding $40 \mathrm{~Hz}$ (Figures $2 \mathrm{C}$ and 3A). Similar results were obtained from subplate neurons in acute neocortical slices harvested postmortem from human fetal brain at gestational week 16-22 (Moore et al., 2009).

In comparison to other neurons in the immature cerebral cortex, subplate cells also reveal the most mature properties in action potential characteristics and in the biophysical properties of voltage-dependent sodium and calcium currents. These observations have been made in developing rodent (Luhmann et al., 2000) as well as in human cerebral cortex (Moore et al., 2009), indicating that these relatively mature functional properties enable subplate cells to transmit afferent neuronal activity faithfully to the developing cortical plate.

Intracellular labeling of single subplate cells with fluorescent dyes or biocytin revealed an extensive neuronal network of dye-coupled neurons in the subplate and cortical plate (Figure 2A). In newborn rats, on average about nine neurons are dye-coupled to a single subplate cell and these gap junction coupled networks are often organized in a columnar manner (Dupont et al., 2006). Whole-cell patch-clamp recordings from pairs of dye-coupled subplate neurons (Figure 2B) allowed a more detailed electrophysiological characterization of the electrical synapses connecting subplate neurons (Figure 2C). The average coupling conductance amounted to about $1.2 \mathrm{nS}$ (Dupont et al., 2006). These data indicate that subplate cells are strongly coupled via electrical synapses and form a functional columnar syncytium with neurons located in the cortical plate. It is tempting to speculate that this early columnar organization results from the radial, column-like neuronal migration of newly generated neurons into the developing neocortex (Noctor et al., 2004), which is also controlled by gap junctional coupling (Elias et al., 2007).

\section{SUBPLATE NEURONS ARE WELL INTEGRATED IN THE DEVELOPING NEOCORTICAL NETWORK}

Electrophysiological and optical imaging recordings further support the hypothesis that subplate neurons are well integrated in the developing cerebral cortex. In vitro intracellular recordings 



FIGURE 2 | Morphological and electrophysiological evidence for electrical coupling between subplate neurons. (A) Intracellular biocytin staining of one subplate neuron (yellow arrow) in the P3 mouse neocortex results in columnar labeling of several dye-coupled cells in the subplate and in the cortical plate. (B) Photograph of two simultaneously recorded P1 subplate neurons, which were both stained with biocytin. (C) Paired current-clamp recordings of the cells shown in (B). Black traces were obtained from the cell marked by black arrow in (B) and red traces are from the cell marked by red arrow. (C1) Injection of a

\section{C1}
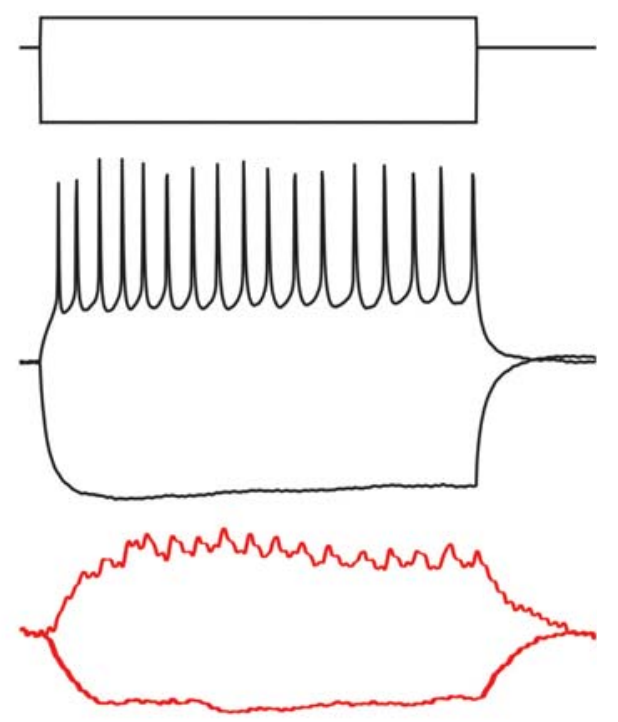

C2

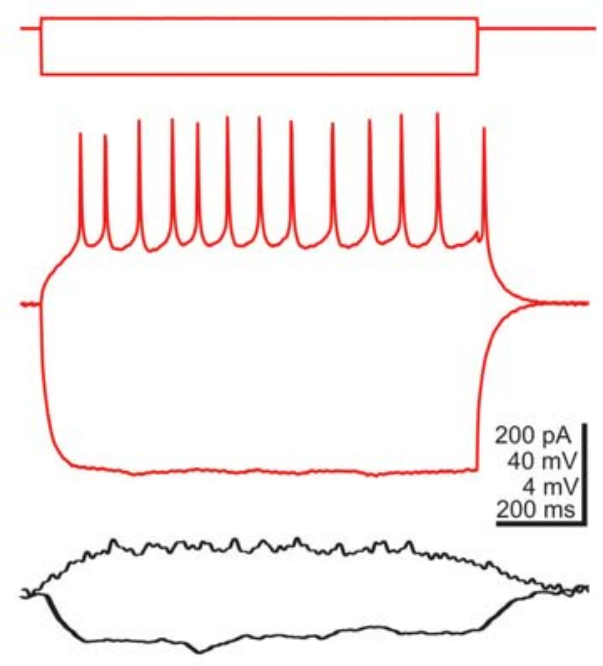

hyperpolarizing or suprathreshold depolarizing current pulse into the cell marked by black arrow causes voltage deflections in the gap junction coupled neuron. (C2) Vice versa, injection of a hyperpolarizing or suprathreshold depolarizing current pulse into the cell marked by red arrow causes voltage deflections in the other neuron. Cortical surface in (A) and (B) is up, action potentials in (C) are truncated. The hyperpolarizing responses in the lower traces are averages of four recordings. Reproduced and modified with permission from (Dupont et al., 2006). and current-source density analyses in late embryonic and early postnatal kitten visual cortex demonstrated that subplate neurons receive functional excitatory synaptic inputs from axons that course in the developing white matter (Friauf et al., 1990; Friauf and Shatz, 1991). Subplate cells in newborn rat somatosensory cortical slices reveal a substantial amount of spontaneous postsynaptic currents
(sPSCs) with different kinetics and pharmacological profile demonstrating that subplate neurons receive functional synaptic inputs mediated by AMPA, NMDA and GABA receptors (Hanganu et al., 2001). A more detailed analysis of the synaptic inputs onto subplate cells could be obtained by electrical stimulation of specific afferent axonal projections (Figures 3B,C) (Staiger et al., 1999). 

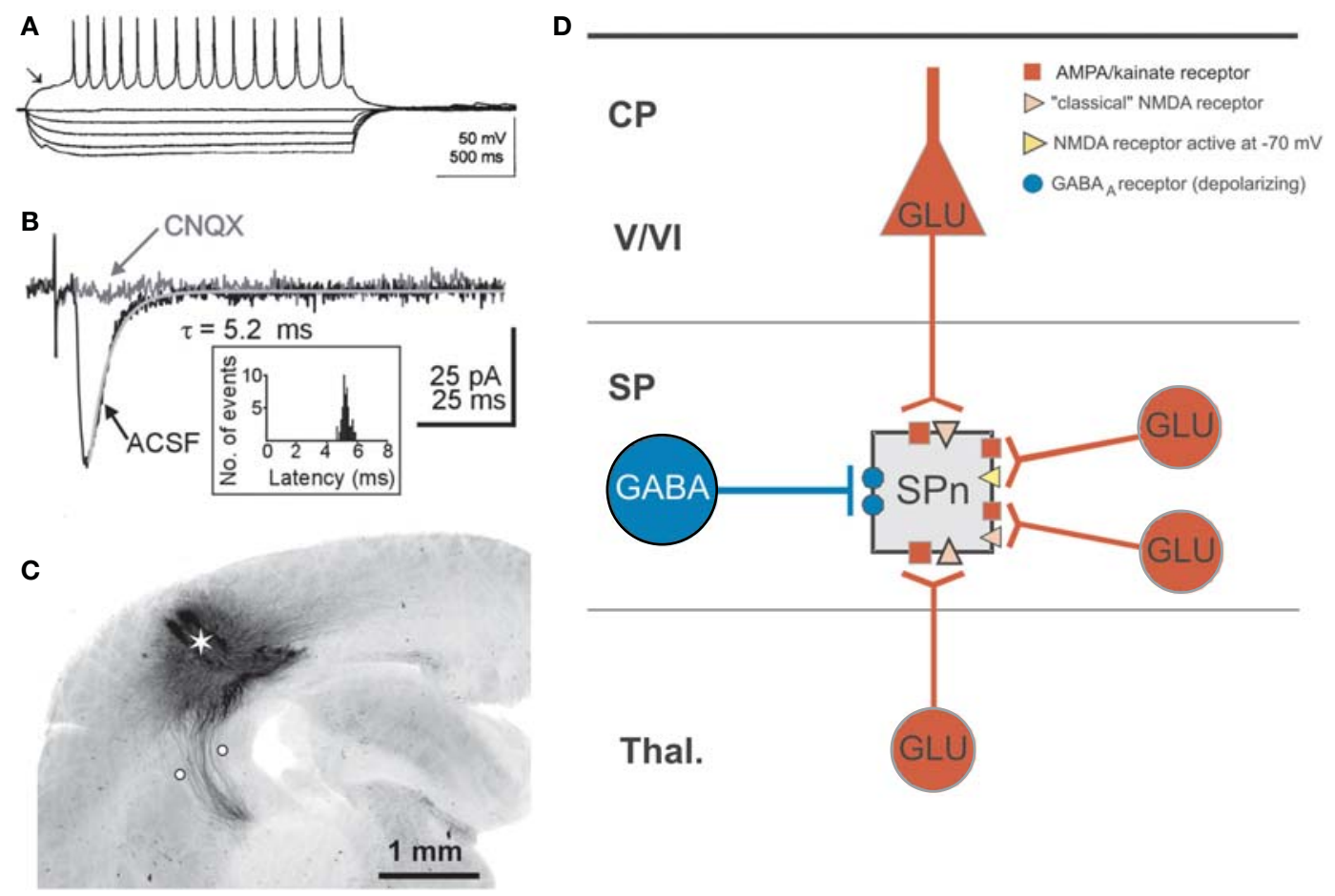

FIGURE 3 | Electrophysiological properties of subplate neurons and their synaptic integration in the developing cerebral cortex. (A) Typical action potential firing pattern of a subplate neuron in the cerebral cortex of a P1 rat. Note repetitive discharge pattern and presence of a prominent $\mathrm{I}_{\mathrm{A}}$ current (arrow). (B) Excitatory postsynaptic currents (EPSCs) recorded in a P3 subplate cell at a holding potential of $-70 \mathrm{mV}$ and elicited by selective electrical stimulation of the thalamocortical input (see C). Synaptic responses were obtained under control conditions in normal extracellular bathing solution and after application of $10 \mu \mathrm{M}$ CNQX to block AMPA/kainate receptors. The EPSC decay could be fitted by a monoexponential function (gray line). The inset shows the unimodal latency distribution of 50 thalamocortical EPSCs recorded

Brief electrical stimulation of the thalamocortical projection elicits in immature rat and cat subplate neurons a fast and reliable excitatory postsynaptic potential/current (EPSP/C), which can blocked by the AMPA/kainate receptor antagonist 6-cyano-7-nitroquinoxaline-2,3-dione (CNQX) (Friauf et al., 1990; Hanganu et al., 2002). Upon membrane depolarization thalamocortical activation elicits a CNQX-insensitive component, which can be blocked by the NMDA receptor antagonist 3-(2-carboxypiperazin-4-yl)propyl-1phosphonic acid (CPP), demonstrating that the thalamic input also activates functional NMDA receptors on subplate cells (Hanganu et al., 2002). These electrophysiological observations from single subplate neurons are further supported by current source-density analyses performed in late embryonic and early postnatal kitten (Friauf and Shatz, 1991) and rat cerebral cortex (Molnár et al., 2003), demonstrating that subplate cells in these species receive a functional thalamic input at earliest stages of neocortical development. Recording of optical images with voltage-sensitive dyes in neocortical slices of prenatal rats have shown that there is a few days delay between the arrival of thalamocortical axons at the subplate at E16 and the appearance of functional thalamocortical synaptic transmission at E19 (Higashi et al., 2002). from one SPn. (C) Photomicrograph of biocytin-stained thalamocortical projections in a 400- $\mu \mathrm{m}$ thick coronal slice from a P1 rat. Asterisk shows extracellular injection site of biocytin crystal and white circles mark position of bipolar electrode to selectively activate the thalamocortical input. (D) Schematic diagram illustrating the distribution of postsynaptic receptors on a subplate neuron for monosynaptic inputs arising from the thalamus (Thal.), the cortical plate (CP) including layers VNI and within the subplate (SP). Note that synaptic inputs from other subplate neurons can lead to activation of depolarizing GABA receptors and NMDA receptors activated at negative membrane potentials. Reproduced and modified with permission from (Luhmann et al., 2000) (A) (Hanganu et al., 2002) (B-D).

Beside a glutamatergic thalamocortical input with relatively mature functional properties (short delay, fast kinetics, reliable responses), subplate cells in newborn rodents receive additional intracortical synaptic inputs from various presynaptic sources (Figure 3D). Local glutamatergic synaptic inputs arise from pyramidal neurons in the cortical plate and from glutamatergic subplate cells, which both activate postsynaptic AMPA/kainate and NMDA receptors (Hanganu et al., 2002). This intra-subplate glutamatergic input differs from the thalamocortical input. Whereas the intra-subplate input reveals a pronounced facilitation when repetitively activated at $10-40 \mathrm{~Hz}$, the thalamocortical input is rather stable or suppressed at these stimulation frequencies (Figure 4) (Hirsch and Luhmann, 2008). Both synaptic inputs also differ in their molecular and developmental profile. The intra-subplate synaptic input can sustain high stimulation frequencies and may boost the thalamocortical input, thereby enhancing activity in the developing neocortical circuit (Hirsch and Luhmann, 2008). Anatomical studies in rodent and human immature cerebral cortex indicate that glutamatergic synaptic inputs most likely also arise from other neocortical sources via corticocortical connections (Ivy and Killackey, 1981; Kostovic 


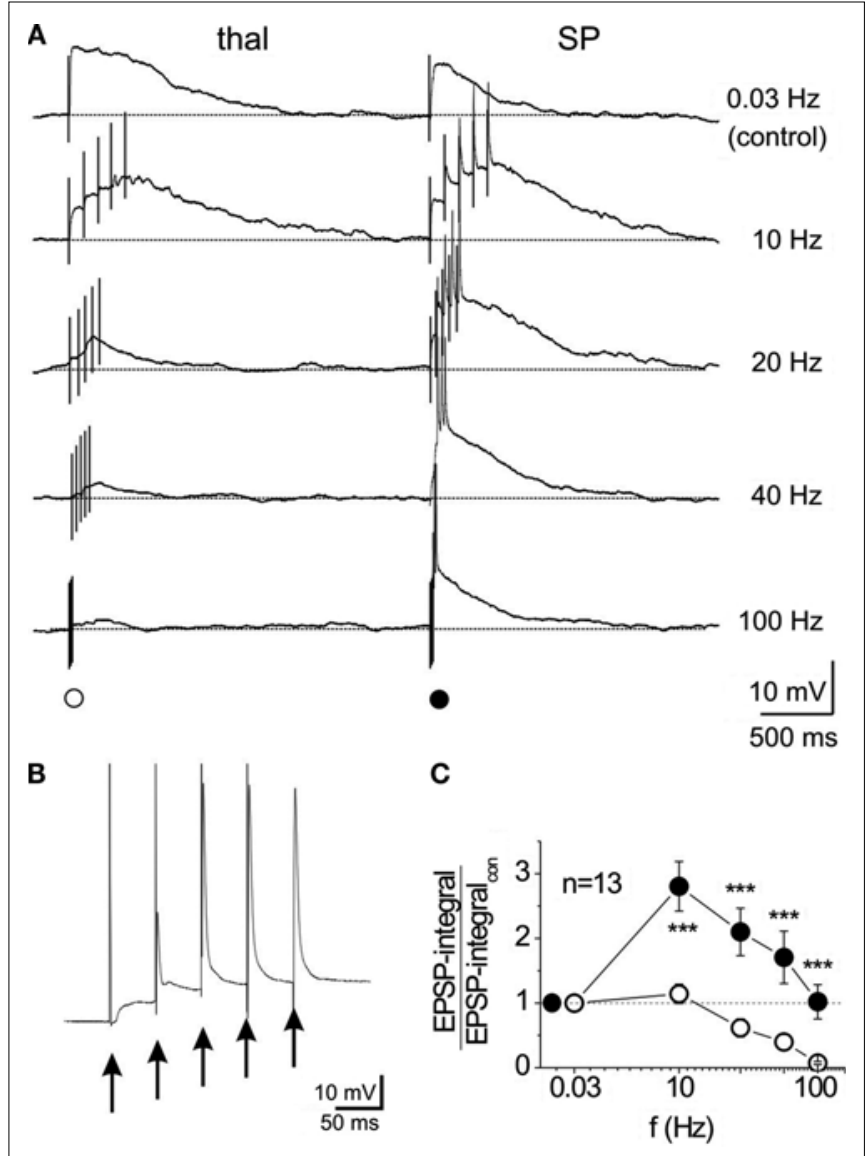

FIGURE 4 | Input-specific differences in temporal summation of NMDA receptor-mediated EPSPs recorded in subplate neurons of the newborn mouse cerebral cortex. Recordings were performed in the presence of CNOX and bicuculline methiodide to isolate NMDA receptor-mediated EPSPs. (A) Five successive stimuli to the thalamic (left) or subplate (right) input reveals prominent temporal summation and repetitive action potentials (truncated) of the subplate input at frequencies between 10 and $40 \mathrm{~Hz}$. All recordings were obtained at a membrane potential of $-80 \mathrm{mV}$. (B) Synaptic response to $20-\mathrm{Hz}$ subplate stimulation at higher resolution [same trace as in (A)]. (C) Quotient between NMDA receptor-EPSP integral and control integral (determined at $0.03 \mathrm{~Hz}$ ) for 13 subplate neurons. Reproduced with permission from Hirsch and Luhmann (2008).

and Jovanov-Milosevic, 2006), but the functional properties of these long-distance synaptic inputs onto subplate cells are currently unknown.

Subplate cells in rodents receive a GABAergic synaptic input from neighbouring GABAergic neurons located in the subplate and probably also in the cortical plate (Figure 3D) (Hanganu et al., 2002). However, as in other immature brain structures, this GABAergic input most likely has a pure excitatory postsynaptic effect (Figure 6 in Hanganu et al., 2002; for review Ben-Ari et al., 2007). An excitatory effect has been demonstrated in subplate cells also for glycine and taurine (Kilb et al., 2008).

Subplate neurons are not only well integrated in the developing cortical circuit, but during certain developmental periods they also receive a very selective input from neuromodulatory brain structures. Both in primates (for review (Rakic, 1995) as well as in rodents (Calarco and Robertson, 1995; Mechawar and Descarries,
2001) the subplate is specifically innervated by cholinergic fibers arising from the basal forebrain and from monoaminergic inputs. The activation of postsynaptic nicotinic acetylcholine receptors elicits in subplate cells a marked depolarization which is largely mediated by the activation of alpha4/beta 2 receptors (Hanganu and Luhmann, 2004). The responsiveness to activation of muscarinic acetylcholine receptors (mAChR) is more complex and reveals a remarkable oscillatory discharge mode of subplate cells (Hanganu et al., 2009).

\section{OSCILLATORY PROPERTIES OF SUBPLATE CELLS}

Application of muscarine to neocortical slices from newborn rats induces in subplate cells repetitive burst discharges with burst frequencies in the range of $20 \mathrm{~Hz}$ (Figure 5A) (Hanganu et al., 2009). Similar burst patterns can be recorded from subplate neurons when the tissue concentration of acetylcholine is raised by application of the cholinesterase inhibitor neostigmine (Figure 5B). These electrophysiological data are further supported by calcium imaging experiments, which demonstrate that activation of muscarinic receptors induces repetitive $\mathrm{Ca}^{2+}$-transients which are highly coordinated within the subplate (Figure 1 in Hanganu et al., 2009). Subplate cells, which express the m1-m5 subunits of the $\mathrm{mAChR}$, are instantly and massively excited upon activation of postsynaptic muscarinic receptors and switch into an oscillatory burst firing mode (Figure 5). Since subplate cells are densely coupled via electrical (Figure 2) and chemical synapses (Figure 3D), these cellular oscillations are synchronized and amplified within the intra-subplate network. Gap junctional coupling, depolarizing GABA actions and a tonic non-synaptic GABA release contribute to the generation and maintenance of the cholinergic network oscillations (Figure 9 in Hanganu et al., 2009).

\section{GABAergic SUBPLATE CELLS DRIVE EARLY CORTICAL NETWORKS}

The crucial role of the subplate in generating cholinergic network oscillations is supported by experiments on thick $(800-1000 \mu \mathrm{m})$ neocortical slices from newborn rodents. Only slices with an intact subplate reveal network oscillations upon activation of muscarinic receptors with carbachol (Dupont et al., 2006). When the subplate is removed, slices do not show any carbachol-induced network oscillations (Figure 6). Furthermore, selective electrical stimulation of the subplate in thick neocortical slices from newborn mice using a multi-electrode array (MEA) also evokes large-scale network oscillations (Figure 7) (Sun and Luhmann, 2007). In a recent study on mouse neocortical slice cultures, Moody and coworkers suggested that the subplate may act as a pacemaker region to generate propagating waves of spontaneous activity in the neonatal cerebral cortex (Lischalk et al., 2009). Early neocortical network oscillations may be triggered by the subplate (Dupont et al., 2006; Sun and Luhmann, 2007) or by the sensory input, i.e. the retina (Hanganu et al., 2006) or the whiskers (Yang et al., 2009). At early developmental stages, the sensory input from the periphery firstly reaches the subplate and is subsequently transmitted to the cortex (Friauf and Shatz, 1991). During this developmental period, intracortical and sensory driven activity patterns may interact. At later stages, the thalamocortical input directly innervates layer IV. 



FIGURE 5 | Subplate neurons in newborn rat cerebral cortex reveal repetitive burst discharges upon activation of postsynaptic cholinergic receptors. (A) Current-clamp whole-cell recording from a P3 subplate cell at a holding potential of $-70 \mathrm{mV}$. Note the long-lasting burst discharge after a single 30-s long bath application of muscarine (marked by a black bar). The recording marked by the dashed box is shown at higher magnification below. Frequency power spectrum of the action potential discharge within one representative burst from the trace above. (B) Current-clamp whole-cell recording from a P2 subplate neuron at a holding potential of $-70 \mathrm{mV}$ displaying the effects of $10 \mu \mathrm{M}$ neostigmine, which blocks endogenous acetylcholine esterase and thereby increases the concentration of acetylcholine in the neocortical slice. Burst discharges appeared 10 min after the beginning of neostigmine application. The recording marked by the dashed box is displayed at higher magnification. Frequency power spectrum of the action potential discharge within burst from the upper trace in (B). Note the similar frequency of the discharge in muscarine- and neostigmine-induced burst discharges. Reproduced and modified with permission from Hanganu et al. (2009).
Electrophysiological and calcium imaging recordings in acute neocortical slices from newborn rodents (Hanganu et al., 2009) as well as calcium imaging data obtained in neocortical cell cultures (Voigt et al., 2001) indicate that GABAergic subplate cells play a central role in generating this neuronal network activity. Voigt et al. (2001) estimated that a minimal number of two GABAergic subplate neurons per square millimeter are required for the occurrence of synchronous network activity. The unique structural and functional properties enable subplate cells to receive, synchronize and amplify the afferent and intrinsic synaptic inputs. It is tempting to speculate on the downstream effects of these early network oscillations in cortical maturation? It has been demonstrated that brain derived neurotrophic factor (BDNF) is released from synaptically localized secretory granules following burst stimulation at $20-50 \mathrm{~Hz}$ (Balkowiec and Katz,
2000; Hartmann et al., 2001) (for review Lessmann et al., 2003). If subplate-driven oscillations contribute to the local secretion of BDNF, the released BDNF may strengthen the synaptic connectivity between neurons in these early ensembles. Beside strengthening synaptic connections via local BDNF release, subplate-driven oscillations may also influence programmed cell death during early developmental stages. We recently demonstrated that the rate of apoptosis in organotypic slice cultures of the neonatal mouse cerebral cortex is regulated by electrical activity patterns, which resemble in many aspects the subplate-driven activity (Heck et al., 2008). This activity-dependent regulation of neuronal apoptosis was at least partly mediated by activation of the BDNF receptor TrkB, indicating that subplate-driven network oscillations may also influence programmed cell death via activity-dependent BDNF release. 
A



FIGURE 6 | Role of the subplate in triggering carbachol-induced network oscillations in the neonatal mouse cerebral cortex. (A) Field potential response to carbachol application in a coronal $800-\mu \mathrm{m}$ thick cortical slab preparation with an intact subplate as shown in Nissl stained
B

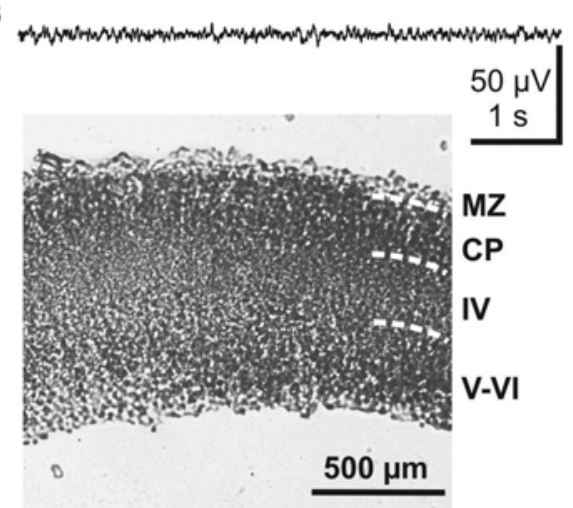

section below. (B) Lack of carbachol-induced activity in a cortical slab preparation, in which the subplate was eliminated. The absence of the subplate was verified by Nissl staining. Reproduced with permission from Dupont et al. (2006).
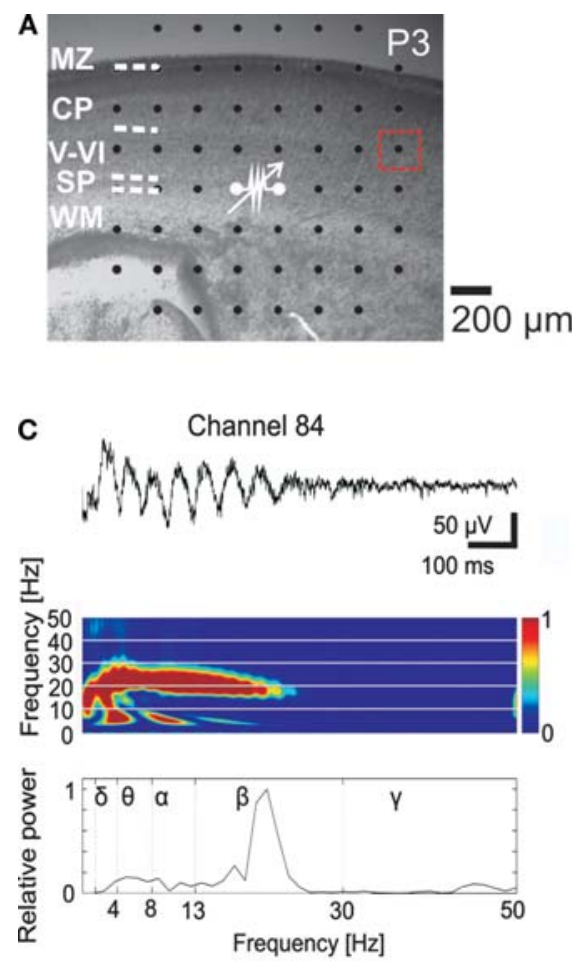

FIGURE 7 | Local electrical stimulation of the subplate elicits propagating network oscillations in the developing cerebral cortical network of the newborn mouse. (A) Photograph of P3 mouse Nissl-stained coronal slice with cortical layers and position of 60-channel multi-electrode array (MEA). (B) MEA recordings from the neocortical slice shown in (A) with site of bipolar stimulation

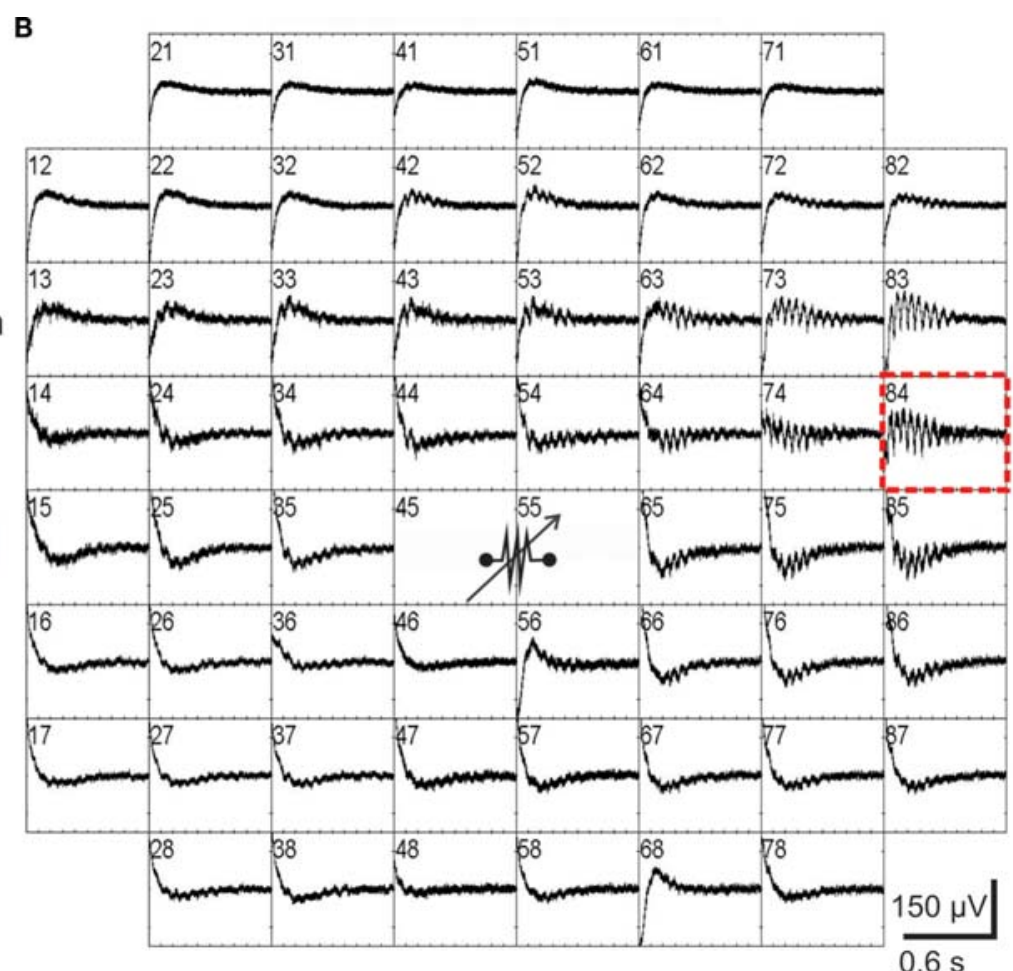

A large proportion of newly generated GABAergic interneurons arising from the medial ganglionic eminence and pyramdial neurons from the ventricular zone must migrate through the subplate on their way to the developing cortical plate (Kriegstein and Noctor, 2004). Therefore the subplate may also have a profound influence in the subplate $(80 \mu \mathrm{A}, 200-\mu$ s duration, $50 \mathrm{~Hz}, 10$ times). Spacing between electrodes is $200 \mu \mathrm{m}$ [see scale bar in (A)]. (C) Recording at electrode number 84 [dotted red rectangle in (A)] shown at higher resolution with corresponding wavelet analysis and Fourier spectrum. Reproduced with permission from Sun and Luhmann (2007). 
Neurotransmitter release in the subplate may rise substantially during oscillatory network activity, thereby activating low affinity or extrasynaptic receptors causing alterations in neuronal migration (Denter et al., 2009).

On the basis of the currently available data we suggest the following model (Figure 8): During early cortical development, in most mammals before birth, subplate cells with relatively mature structural properties (elaborated dendritic tree, complex axonal projections, mature symmetrical and asymmetrical synapses) receive a functional glutamatergic synaptic input from specific thalamic nuclei and a selective input from neuromodulatory systems (e.g. cholinergic inputs from the basal forebrain). In rodents, subplate neurons are densely interconnected via electrical and chemical synapses and upon activation of muscarinic (and probably also other metabotropic receptors (Wagner and Luhmann, 2006) discharge in repetitive $\sim 20 \mathrm{~Hz}$ bursts (lower inset in Figure 8). GABAergic subplate neurons releasing GABA in a synaptic ( 1 in Figure 8) and tonic non-synaptic manner ( 2 in Figure 8 ) facilitate the generation of oscillatory network activity (Hanganu et al., 2009). Intra-subplate connections arising from glutamatergic subplate cells may boost the subplate activity in the $10-40 \mathrm{~Hz}$ frequency range (Hirsch and Luhmann, 2008). Subplate cells are dye-coupled to cortical plate neurons in a columnar manner (Dupont et al., 2006) and faithfully transmit synchronized $10-20 \mathrm{~Hz}$ network oscillations generated and amplified in the subplate to the cortical plate and marginal zone (upper inset in Figure 8) (Dupont et al., 2006; Wagner and Luhmann, 2006; Sun and Luhmann, 2007).

Elimination or interruption of the subplate prevents the generation of the subplate-driven synchronized activity patterns and disturbs the maturation of the columnar architecture (Ghosh and Shatz, 1992; Kanold et al., 2003; Kanold and Shatz, 2006). Under normal conditions and with further development, subplate cells disappear by apoptosis (Ferrer et al., 1990; Price et al., 1997; Arias et al., 2002) or transform into white matter interstitial cells (Valverde and Facal-Valverde, 1988; Valverde et al., 1995) or layer VIb (layer VII) neurons (Woo et al., 1991; Reep, 2000). In the normal mature cerebral cortex, subplate neurons have lost their capabilities to receive and amplify incoming neuronal activity and to generate synchronized network oscillations. However, as already suggested by Jones (1995), disturbances in the pattern of programmed cell death in the subplate may cause a failure to establish normal patterns of connections in the overlying cerebral cortex, leading to long-term neurological deficits such as schizophrenia. Abnormal placement of (surviving subplate?) neurons in the white matter and atypical circuits have been observed in the prefrontal cortex of schizophrenic patients (Akbarian et al., 1996; Kirkpatrick et al., 1999; Bunney and Bunney, 2000). It has been further suggested that subplate-like neurons may persist in cortical dysplasia and contribute to the manifestation of pharmacoresistant epilepsy in adults

\section{REFERENCES}

Aboitiz, F., and Montiel, J. (2007). Origin and evolution of the vertebrate telencephalon, with special reference to the mammalian neocortex. Adv. Anat. Embryol. Cell Biol. 193, 1-112.

Akbarian, S., Kim, J. J., Potkin, S. G., Hetrick, W. P., Bunney, W. E. Jr., and
Jones, E. G. (1996). Maldistribution of interstitial neurons in prefrontal white matter of the brains of schizophrenic patients. Arch. Gen. Psychiatry 53, 425-436.

Allendoerfer, K. L., and Shatz, C. J. (1994). The subplate, a transient neocortical structure: Its role in the development

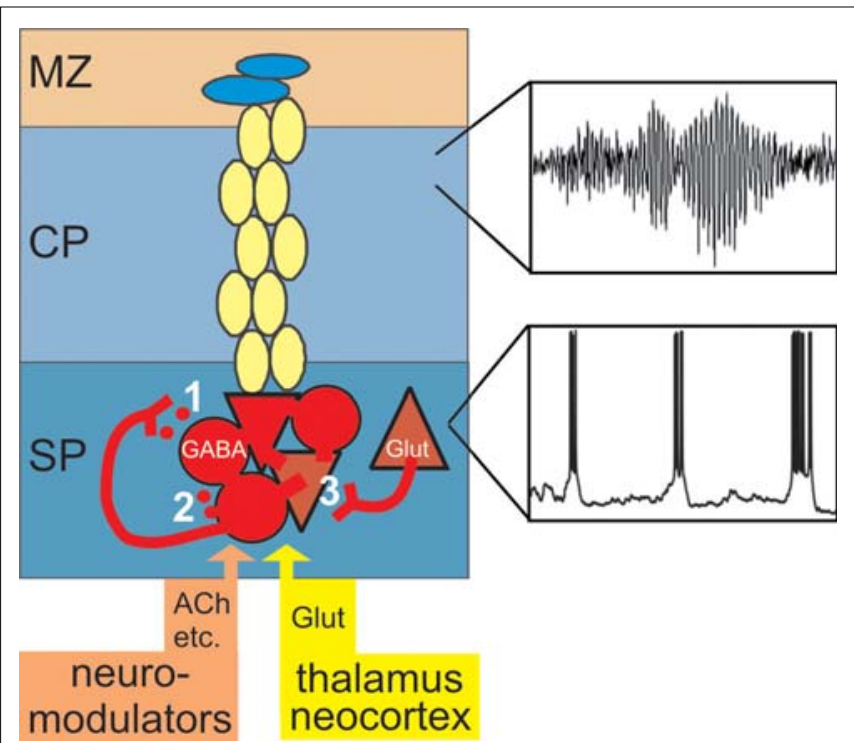

FIGURE 8 |Amplification of afferent and intracortical activity by the subplate. During early cortical development the subplate receives a transient and selective synaptic input from neuromodulatory systems, from the sensory periphery via specific thalamic nuclei and via corticocortical fibers from other neocortical areas. Subplate cells are capable to fire repetitive action potentials (Figure $\mathbf{3 A}$ ) and upon activation of cholinergic postsynaptic receptors discharge in repetitive bursts (lower inset and Figure 5). GABAergic subplate neurons release GABA in an activity-dependent (1) and tonic (2) manner thereby inducing a postsynaptic excitatory response. Glutamatergic subplate neurons boost neuronal network activity in the $10-40 \mathrm{~Hz}$ frequency range. Subplate neurons are not only coupled via these excitatory synaptic circuits, but also via gap junctions (Figure 2). Chemical and electrical synapses contribute to the generation of subplate-driven oscillatory activity which is transmitted to the gap junctional coupled network in the cortical plate (Figure 2A) and marginal zone and induces 10-20 Hz neocortical network oscillations (upper inset).

(Cepeda et al., 2007). Interestingly in the resectioned human tissue GABA application induced depolarizing postsynaptic responses and spontaneous GABAergic synaptic potentials even elicited action potentials (Cepeda et al., 2007).

In summary, experimental data indicate that subplate cells, most likely GABAergic subplate neurons, play an important role in the generation of early synchronized network activity and in the normal development of the neocortical network and columnar architecture. Clinical evidence suggests that subplate cells in the mature cortex contribute to the manifestation of abnormal neuronal circuits, pathological activities and long-term neurological deficits.

\section{ACKNOWLEDGMENT}

This work was supported by DFG grants to the authors.

of connections between thalamus and cortex. Annu. Rev. Neurosci. 17, 185-218.

Aoki, C. (1997). Postnatal changes in the laminar and subcellular distribution of NMDA-R1 subunits in the cat visual cortex as revealed by immuno-electron microscopy. Dev. Brain Res. 98, 41-59.
Arias, M. S. Baratta, J., Yu, J., and Robertson, R. T. (2002). Absence of selectivity in the loss of neurons from the developing cortical subplate of the rat. Dev. Brain Res. 139, 331-335.

Balkowiec, A., and Katz, D. M. (2000). Activity-dependent release of endogenous brain-derived neurotrophic 
factor from primary sensory neurons detected by ELISA in situ. J. Neurosci. 20, 7417-7423.

Ben-Ari, Y., Gaiarsa, J. L., Tyzio, R., and Khazipov, R. (2007). GABA: a pioneer transmitter that excites immature neurons and generates primitive oscillations. Physiol. Rev. 87, 1215-1284.

Bunney, W. E., and Bunney, B. G. (2000). Evidence for a compromised dorsolateral prefrontal cortical parallel circuit in schizophrenia. Brain Res. Rev. 31, 138-146.

Bystron, I., Blakemore, C., and Rakic, P. (2008). Development of the human cerebral cortex: Boulder Committee revisited. Nat. Rev. Neurosci. 9, 110-122.

Calarco, C. A., and Robertson, R. T. (1995). Development of basal forebrain projections to visual cortex: DiI studies in rat. J. Comp. Neurol. 354, 608-626.

Catalano, S. M., Chang, C. K., and Shatz, C. J. (1997). Activity-dependent regulation of NMDAR1 immunoreactivity in the developing visual cortex. J. Neurosci. 17, 8376-8390.

Cepeda, C., Andre, V. M., Wu, N., Yamazaki, I., Uzgil, B., Vinters, H. V., Levine, M. S., and Mathern, G. W. (2007). Immature neurons and GABA networks may contribute to epileptogenesis in pediatric cortical dysplasia. Epilepsia 48(Suppl. 5), 79-85.

Chun, J.J., Nakamura, M. J., and Shatz, C. J. (1987). Transient cells of the developing mammalian telencephalon are peptide-immunoreactive neurons. Nature 325, 617-620.

Chun, J. J., and Shatz, C. J. (1988). Redistribution of synaptic vesicle antigens is correlated with the disappearance of a transient synaptic zone in the developing cerebral cortex. Neuron 1, 297-310.

Clancy, B., and Cauller, L. J. (1999). Widespread projections from subgriseal neurons (Layer VII) to layer I in adult rat cortex. J. Comp. Neurol. 407, 275-286.

Crandall, J. E., and Caviness, V. S. J. (1984). Axon strata of the cerebral wall in embryonic mice. Brain Res. 316, 185-195.

De Carlos, J. A., and O'Leary, D. D. M. (1992). Growth and targeting of subplate axons and establishment of major cortical pathways. J. Neurosci. 12, 1194-1211.

Del Río, J. A., Martínez, A., Auladell, C., and Soriano, E. (2000).Developmental history of the subplate and developing white matter in the murine neocortex. Neuronal organization and relationship with the main afferent systems at embryonic perinatal stages. Cereb. Cortex 10, 784-801.
Denter, D., Heck, N., Riedemann, T., Kilb, W., and Luhmann, H. J. (2009). GABAc receptors are functionally expressed in the intermediate zone and regulate radial migration in the embryonic mouse neocortex. Neuroscience. (submitted).

Dupont, E., Hanganu, I. L., Kilb, W., Hirsch, S., and Luhmann, H. J. (2006). Rapid developmental switch in the mechanisms driving early cortical columnar networks. Nature 439, 79-83.

Elias, L. A., Wang, D. D., and Kriegstein, A. R. (2007). Gap junction adhesion is necessary for radial migration in the neocortex. Nature 448, 901-907.

Ferrer, I., Bernet, E., Soriano, E., Del Rio, T., and Fonseca, M. (1990). Naturally occurring cell death in the cerebral cortex of the rat and removal of dead cells by transitory phagocytes. Neuroscience 39, 451-458.

Finney, E. M., Stone, J. R., and Shatz, C. J. (1998). Major glutamatergic projection from subplate into visual cortex during development. J. Comp. Neurol. 398, 105-118.

Friauf,E., McConnell, S. K., and Shatz, C. J. (1990). Functional synaptic circuits in the subplate during fetal and early postnatal development of cat visual cortex. J. Neurosci. 10, 2601-2613.

Friauf,E., and Shatz, C. J.(1991).Changing patterns of synaptic input to subplate and cortical plate during development of visual cortex. J. Neurophysiol. 66, 2059-2071.

Furuta, A., and Martin, L. J. (1999). Laminar segregation of the cortical plate during corticogenesis is accompanied by changes in glutamate receptor expression. J. Neurobiol. 39, 67-80.

Ghosh, A., Antonini, A., McConnell, S. K., and Shatz, C. J. (1990). Requirements of subplate neurons in the formation of thalamocortical connections. Nature 347, 179-181.

Ghosh, A., and Shatz, C. J. (1992). Involvement of subplate neurons in the formation of ocular dominance columns. Science 255, 1441-1443.

Hanganu, I. L., Ben-Ari, Y., and Khazipov, R. (2006). Retinal waves trigger spindle bursts in the neonatal rat visual cortex. J. Neurosci. 26, 6728-6736.

Hanganu,I.L., Kilb, W., and Luhmann, H. J. (2001).Spontaneous synaptic activity of subplate neurons in neonatal rat somatosensory cortex. Cereb. Cortex 11, 400-410.

Hanganu,I.L., Kilb, W., andLuhmann, H. J. (2002). Functional synaptic projections onto subplate neurons in neonatal rat somatosensory cortex. J. Neurosci. 22, 7165-7176.
Hanganu, I. L., and Luhmann, H. J. (2004). Functional nicotinic acetylcholine receptors on subplate neurons in neonatal rat somatosensory cortex. J. Neurophysiol. 92, 189-198.

Hanganu, I. L., Okabe, A., Lessmann, V. and Luhmann, H. J. (2009). Cellular mechanisms of subplate-driven and cholinergic input-dependent network activity in the neonatal rat somatosensory cortex. Cereb. Cortex 19, 89-105.

Hartmann, M., Heumann, R., and Lessmann, V. (2001). Synaptic secretion of BDNF after high-frequency stimulation of glutamatergic synapses. EMBO J. 20, 5887-5897.

Heck, N., Golbs, A., Riedemann, T. Sun, J. J., Lessmann, V., and Luhmann, H. J. (2008). Activitydependent regulation of neuronal apoptosis in neonatal mouse cerebra cortex. Cereb. Cortex 18, 1335-1349.

Heck, N., Kilb, W., Reiprich, P., Kubota, H. Furukawa, T., Fukuda, A., and Luhmann, H. J. (2007). GABA-A receptors regulate neocortical neuronal migration in vitro and in vivo. Cereb. Cortex 17, 138-148.

Herrmann, K. (1996). Differential distribution of AMPA receptors and glutamate during pre- and postnatal development in the visual cortex of ferrets. J. Comp. Neurol. 375, 1-17.

Herrmann, K., Antonini, A., and Shatz, C. J. (1994). Ultrastructural evidence for synaptic interactions between thalamocortical axons and subplate neurons. Eur. J. Neurosci. 6, 1729-1742.

Hevner, R. F., Daza, R. A., Englund, C. Kohtz, J., and Fink, A. (2004). Postnatal shifts of interneuron position in the neocortex of normal and reeler mice: evidence for inward radial migration. Neuroscience 124, 605-618.

Higashi, S., Molnár, Z., Kurotani, T., and Toyama, K. (2002). Prenatal development of neural excitation in rat thalamocortical projections studied by optical recording. Neuroscience 115 1231-1246.

Higo, S., Udaka, N., and Tamamaki, N. (2007). Long-range GABAergic projection neurons in the cat neocortex. J. Comp. Neurol. 503, 421-431.

Hirsch, S., and Luhmann, H. J. (2008) Pathway-specificity in N-methyld-aspartate receptor-mediated synaptic inputs onto subplate neurons. Neuroscience 153, 1092-1102.

Hoerder-Suabedissen, A., Wang, W. Z., Lee, S., Davies, K. E., Goffinet, A., Rakic, S., Parnavelas, J., Reim, K., Nicolic, M., Paulsen, O., and Molnár, Z. (2009). Novel markers reveal subpopulations of subplate neurons in the murine cerebral cortex. Cereb. Cortex 19, 1738-1750.
Huntley, G. W., De Blas, A. L., and Jones, E. G. (1990). GABA receptor immunoreactivity in adult and developing monkey sensory-motor cortex. Exp. Brain Res. 82, 519-535.

Ivy, G. O., and Killackey, H. P. (1981). The ontogeny of the distribution of callosal projection neurons in the rat parietal cortex. J. Comp. Neurol. 195, 367-389.

Jones, E. G. (1995). Cortical development and neuropathology in schizophrenia. Ciba Found. Symp. 193, 277-295.

Kanold, P. O., Kara, P., Reid, R. C., and Shatz, C. J. (2003). Role of subplate neurons in functional maturation of visual cortical columns. Science 301, 521-525.

Kanold, P. O., and Shatz, C. J. (2006). Subplate neurons regulate maturation of cortical inhibition and outcome of ocular dominance plasticity. Neuron 51, 627-638.

Kilb, W., Hanganu, I. L., Okabe, A., Sava, B. A., Shimizu-Okabe, C., Fukuda,A., and Luhmann, H.J. (2008) Glycine receptors mediate excitation of subplate neurons in neonatal rat cerebral cortex. J. Neurophysiol. 100, 698-707.

Kim, G. J.,Shatz, C. J., and McConnell, S. K. (1991). Morphology of pioneer and follower growth cones in the developing cerebral cortex. J. Neurobiol. 22, 629-642.

Kirkpatrick, B., Conley, R. C., Kakoyannis, A., Reep, R. L., and Roberts, R. C. (1999). Interstitial cells of the white matter in the inferior parietal cortex in schizophrenia: an unbiased cell-counting study. Synapse 34, 95-102.

Kostovic, I., and Jovanov-Milosevic, N. (2006). The development of cerebral connections during the first 20-45 weeks' gestation. Semin. Fetal Neonatal Med. 11, 415-422.

Kostovic, I., Judas, M., Rados, M., and Hrabac, P. (2002). Laminar organization of the human fetal cerebrum revealed by histochemical markers and magnetic resonance imaging. Cereb. Cortex 12, 536-544.

Kostovic, I., and Molliver, M. E. (1974). A new interpretation of the laminar development of cerebral cortex: synaptogenesis in different layers of neopallium in the human fetus. Anat. Rec. 178, 395.

Kostovic, I., and Rakic, P. (1980). Cytology and time of origin of interstitial neurons in the white matter in infant and adult human and monkey telencephalon. J. Neurocytol. 9, 219-242.

Kostovic, I., and Rakic, P. (1990). Developmental history of the transient subplate zone in the visual and somatosensory cortex of the macaque 
monkey and human brain. J. Comp. Neurol. 297, 441-470.

Kriegstein, A. R., and Noctor, S. C. (2004). Patterns of neuronal migration in the embryonic cortex. Trends Neurosci.27, 392-399.

Lavdas, A. A., Grigoriou, M., Pachnis, V., and Parnavelas, J. G. (1999). The medial ganglionic eminence gives rise to a population of early neurons in the developing cerebral cortex. J. Neurosci. 19, 7881-7888

Lessmann, V., Gottmann, K., and Malcangio, M. (2003). Neurotrophin secretion: current facts and future prospects. Prog. Neurobiol. 69, 341-374.

Lischalk, J. W., Easton, C. R., and Moody, W. J. (2009). Bilaterally propagating waves of spontaneous activity arising from discrete pacemakers in the neonatal mouse cerebral cortex. Dev. Neurobiol. 69, 407-414.

Luhmann, H. J., Reiprich, R. A., Hanganu, I. L., and Kilb, W. (2000). Cellular physiology of the neonatal rat cerebral cortex: Intrinsic membrane properties, sodium and calcium currents. J. Neurosci. Res. 62, 574-584.

Lund, R. D., and Mustari, M. J. (1977). Development of the geniculocortical pathway in rats. J. Comp. Neurol. 173 , 289-306.

Luskin, M. B., and Shatz, C. J. (1985). Studies of the earliest generated cells of the cat's visual cortex: cogeneration of subplate and marginal zones. J. Neurosci. 5, 1062-1075.

Manent, J. B., Demarque, M., Jorquera, I., Pellegrino, C., Ben-Ari, Y., Aniksztejn, L., and Represa, A. (2005). A noncanonical release of GABA and glutamate modulates neuronal migration. J. Neurosci. 25, 4755-4765.

Manent, J. B., Jorquera, I., Ben-Ari, Y., Aniksztejn, L., and Represa, A. (2006). Glutamate acting on AMPA but not NMDA receptors modulates the migration of hippocampal interneurons. J. Neurosci. 26, 5901-5909.

Manent, J. B., and Represa, A. (2007). Neurotransmitters and brain maturation: early paracrine actions of GABA and glutamate modulate neuronal migration. Neuroscientist 13 , 268-279.

McConnell, S. K., Ghosh, A., and Shatz, C. J. (1989). Subplate neurons pioneer the first axon pathway from the cerebral cortex. Science 245, 978-982.

McConnell, S. K., Ghosh, A., and Shatz, C. J. (1994). Subplate pioneers and the formation of descending connections from cerebral cortex. J. Neurosci. 14, 1892-1907.

Mechawar, N., and Descarries, L. (2001). The cholinergic innervation develops early and rapidly in the rat cerebral cortex: a quantitative immunocytochemical study. Neuroscience 108 555-567.

Meinecke, D. L., and Rakic, P. (1992). Expression of GABA and $\mathrm{GABA}_{\mathrm{A}}$ receptors by neurons of the subplate zone in developing primate occipital cortex: evidence for transient local circuits. J. Comp. Neurol. 317, 91-101.

Molnár, Z. (1998). Development of Thalamocortical Connections. Berlin, Heidelberg, Springer.

Molnár, Z., Kurotani, T., Higashi, S., Yamamoto, N., and Toyama, K. (2003). Development of functional thalamocortical synapses studied with current source-density analysis in whole forebrain slices in the rat. Brain Res. Bull. 60, 355-371.

Moore, A. R., Filipovic, R., Mo, Z., Rasband, M. N., Zecevic, N., and Antic, S. D. (2009). Electrical excitability of early neurons in the human cerebral cortex during the second trimester of gestattion. Cereb. Cortex 19, 1795-1805.

Mrzljak, L., Uylings, H. B., Van Eden, C. G., and Judas, M. (1990). Neuronal development in human prefrontal cortex in prenatal and postnatal stages. Prog. Brain Res. 85, 185-222.

Mrzljak, L., Uylings, H. B. M., Kostovic, I., and Van Eden, C. G. (1992). Prenatal development of neurons in the human prefrontal cortex. II. A quantitative Golgi study. J. Comp. Neurol. 316, 485-496.

Noctor, S. C., Martinez-Cerdeno, V., Ivic, L., and Kriegstein, A. R. (2004). Cortical neurons arise in symmetric and asymmetric division zones and migrate through specific phases. Nat. Neurosci. 7, 136-144.

Price, D. J., Aslam, S., Tasker, L., and Gillies, K. (1997). Fates of the earliest generated cells in the developing murine neocortex. J. Comp. Neurol. $377,414-422$.

Rakic, P. (1977). Prenatal development of the visual system in rhesus monkey. Philos. Trans. R Soc. Lond., B, Biol. Sci. $278,245-260$

Rakic, P. (1983). Geniculo-cortical connections in primates: normal and experimentally altered development. Prog. Brain Res. 58, 393-404.
Rakic, P. (1995). A small step for the cell, a giant leap for mankind: A hypothesis of neocortical expansion during evolution. Trends Neurosci. 18, 383-388.

Reep, R. L. (2000). Cortical layer VII and persistent subplate cells in mammalian brains. Brain Behav. Evol. 56, 212-234.

Reiprich, P., Kilb, W., and Luhmann, H. J. (2005). Neonatal NMDA receptor blockade disturbs neuronal migration in rat somatosensory cortex in vivo. Cereb. Cortex 15, 349-358.

Schlumpf, M., Richards, J. G. Lichtensteiger, W., and Möhler, H. (1983). An autoradiographic study of the prenatal development of benzodiazepine-binding sites in rat brain. J. Neurosci. 3, 1478-1487.

Staiger, J. F., Kötter, R., Zilles, K., and Luhmann, H. J. (1999). Connectivity in the somatosensory cortex of the adolescent rat: an in vitro biocytin study. Anat. Embryol. 199, 357-365.

Sun, J. J., and Luhmann, H. J. (2007). Spatio-temporal dynamics of oscillatory network activity in the neonatal mouse cerebral cortex. Eur. J. Neurosci. 26, 1995-2004.

Tomioka, R., Okamoto, K., Furuta, T., Fujiyama, F., Iwasato, T., Yanagawa, Y., Obata, K., Kaneko, T., and Tamamaki, N. (2005). Demonstration of long-range GABAergic connections distributed throughout the mouse neocortex. Eur. J. Neurosci. 21 , 1587-1600.

Uylings, H. B. M., Van Eden, C. G., Parnavelas, J. G., and Kalsbeek, A. (1990). The prenatal and postnatal development of rat cerebral cortex. In The Cerebral Cortex of the Rat, B. Kolb and R. C. Tees, eds (Cambridge, MIT Press), pp. 35-76.

Valverde, F., Facal Valverde, M. V., Santacana, M., and Heredia, M. (1989). Development and differentiation of early generated cells of sublayer VIb in the somatosensory cortex of the rat: a correlated Golgi and autoradiographic study. J. Comp. Neurol. 290, 118-140.

Valverde, F., and Facal-Valverde, M. V. (1988). Postnatal development of interstitial (subplate) cells in the white matter of the temporal cortex of kittens: a correlated Golgi and electron microscopic study. J. Comp. Neurol. 269, 168-192.

Valverde, F., López-Mascaraque, L., Santacana, M., and De Carlos, J. A. (1995). Persistence of early-generated neurons in the rodent subplate: Assessment of cell death in neocortex during the early postnatal period. J. Neurosci. 15, 5014-5024.

Voigt, T., Opitz, T., and De Lima, A. D. (2001).Synchronous oscillatory activity in immature cortical network is driven by GABAergic preplate neurons. J. Neurosci. 21, 8895-8905.

Wagner, J., and Luhmann, H. J. (2006). Activation of metabotropic glutamate receptors induces propagating network oscillations in the intact cerebral cortex of the newborn mouse. Neuropharmacology 51, 848-857.

Wahle, P., Lübke, J., and Naegele, J. R. (1994). Inverted pyramidal neurons and interneurons in cat cortical subplate zone are labelled by monoclonal antibody SP1. Eur. J. Neurosci. 6, 1167-1178.

Wahle, P., Meyer, G., Wu, J. Y., and Albus, K. (1987). Morphology and axon terminal pattern of glutamate decarboxylase- immunoreactive cell types in the white matter of the cat occipital cortex during early postnatal development. Brain Res. 433, 53-61.

Woo, T. U., Beale, J. M., and Finlay, B. L. (1991). Dual fate of subplate neurons in a rodent. Cereb. Cortex 1, 433-443.

Yang, J.W., Hanganu-Opatz, I. L., Sun, J. J., and Luhmann, H. J. (2009). Three patterns of oscillatory activity differentially synchronize developing neocortical networks in vivo. J. Neurosci. 29, 9011-9025.

Conflict of Interest Statement: The authors declare that the research presented in this paper was conducted in the absence of any commercial or financial relationships that could be construed as a potential conflict of interest.

Received: 07 July 2009; paper pending published: 25 July 2009; accepted:04 September 2009; published online: 07 October 2009. Citation: Luhmann HJ, Kilb $W$ and Hanganu-Opatz IL (2009) Subplate cells: amplifiers of neuronal activity in the developing cerebral cortex. Front. Neuroanat. 3:19. doi: 10.3389/neuro.05.019.2009 Copyright $\odot 2009$ Luhmann, Kilb and Hanganu-Opatz. This is an open-access article subject to an exclusive license agreement between the authors and the Frontiers Research Foundation, which permits unrestricted use, distribution, and reproduction in any medium, provided the original authors and source are credited. 